\title{
Effect of long term oxygen therapy on survival in patients with chronic obstructive pulmonary disease with moderate hypoxaemia
}

\author{
Dorota Górecka, Katarzyna Gorzelak, Paweł Śliwiński, Mirosław Tobiasz, Jan Zieliński
}

\begin{abstract}
Background - To date only two controlled studies have been published on the effects of domiciliary oxygen treatment on survival in patients with chronic obstructive pulmonary disease (COPD) with advanced respiratory failure. The survival in such patients despite oxygen treatment remains poor. The prescription of long term oxygen therapy (LTOT) in less severe disease remains controversial. The aim of this study was to evaluate the rationale for prescribing oxygen to patients with COPD with moderate hypoxaemia.
\end{abstract}

Methods - One hundred and thirty five patients with COPD, with $\mathrm{PaO}_{2} 7.4-8.7 \mathrm{kPa}$ (56-65 mmHg) and advanced airflow limitation (mean (SD) forced expiratory volume in one second $\left.\left(\mathrm{FEV}_{1}\right) 0.83(0.28) 1\right)$, were randomly allocated to a control $(n=$ 67) and LTOT $(n=68)$ group. The patients were followed every three months for at least three years or until death.

Results -The cumulative survival rate was $88 \%$ at one year, $77 \%$ at two years, and $66 \%$ at three years. No significant differences were found in survival rates between patients treated with LTOT and controls, nor did longer oxygen use (over 15 hours per day) improve survival. Younger age, better spirometric values, and higher body mass index predicted better survival.

Conclusions - Domiciliary oxygen treatment does not prolong survival in patients with COPD with moderate hypoxaemia. Airway limitation seems to determine survival in this group of patients.

(Thorax 1997;52:674-679)

Respiratory Medicine, Institute of

Tuberculosis and Lung

Diseases, 01-138

Warsaw, Poland

D Górecka

K Gorzelak

P Śliwiński

M Tobiasz

J Zieliński

Correspondence to: Dr D Górecka.

Received 9 July 1996 Returned to author 21 October 1996

Revised version received

29 January 1997

Accepted for publication

30 January 1997
Patients with COPD are usually given LTOT in the advanced stage of the disease and long term survival in such patients, despite oxygen treatment, remains poor. ${ }^{1-4}$ It has been suggested that LTOT should be prescribed earlier in the natural history of the disease, ${ }^{56}$ and in some countries oxygen is also prescribed to patients with moderate hypoxaemia $\left(\mathrm{PaO}_{2}\right.$ $7.4-8.7 \mathrm{kPa}(56-65 \mathrm{mmHg})) .{ }^{78}$ However, no controlled studies have been reported to show that the implementation of LTOT in this group of patients also prolongs life. The aim of our study was therefore to evaluate the rationale of prescribing oxygen in patients with COPD with moderate hypoxaemia.

\section{Methods}

One hundred and thirty five consecutive patients with COPD referred to nine regional LTOT centres in Poland with moderate hypoxaemia $\left(\mathrm{PaO}_{2} \quad 7.4-8.7 \mathrm{kPa}(56-65 \mathrm{mmHg})\right)$ entered the study in the years 1987-92 and were followed up to the end of 1994 . The organisation of domiciliary oxygen therapy in Poland and qualification procedures have been described previously. ${ }^{910}$

We included patients with COPD as a single diagnosis, aged between 40 and 80 years, with airway limitation defined by $\mathrm{FEV}_{1} / \mathrm{VC}$ post bronchodilator of $<70 \%$. Patients with serious disease of organs other than the lungs that might influence survival were excluded from the study. Baseline studies included a complete history, physical examination, and basic laboratory tests. Spirometric measurements and blood gas tensions were measured twice, at least three weeks apart, in all patients, along with a chest radiograph and ECG before entering the study. Patients were randomly allocated to receive either conventional treatment (controls) or conventional treatment plus oxygen (LTOT). Randomisation schedules were developed centrally. Treatment assignments were computer generated by random numbers, with an equal number of patients in the control and treatment groups. Usual treatment consisted of bronchodilators (theophylline, $\beta_{2}$ agonists, and anticholinergic drugs). Antibiotics, diuretics, and corticosteroids were prescribed at the discretion of the physician. Prolonged use of corticosteroids was defined 
Table 1 Mean (SD) clinical characteristics of 135 patients with COPD at entry to the study

\begin{tabular}{|c|c|c|c|}
\hline Variable & $\begin{array}{l}\text { Total } \\
(n=135)\end{array}$ & $\begin{array}{l}\text { Control group } \\
(n=67)\end{array}$ & $\begin{array}{l}\text { LTOT group } \\
(n=68)\end{array}$ \\
\hline Age (years) & $61.2(8.5)$ & $62.4(8.2)$ & $60.1(8.8)$ \\
\hline & $103 / 32$ & $52 / 15$ & $51 / 17$ \\
\hline $\mathrm{BMI}\left(\mathrm{kg} / \mathrm{m}^{2}\right)$ & $23.6(6.0)$ & $23.3(4.0)$ & $23.8 \quad(5.1)$ \\
\hline $\mathrm{PaO}_{2}(\mathrm{kPa} / \mathrm{mmHg})$ & $8.0(0.4) / 60.4(2.8)$ & $8.2(0.4) / 61.3(2.7)$ & $7.9(0.4) / 59.5(2.7)^{*}$ \\
\hline $\mathrm{PaCO}_{2}(\mathrm{kPa} / \mathrm{mmHg})$ & $5.9(0.9) / 44.1(6.7)$ & $5.7(0.9) / 42.8(6.6)$ & $6.0(0.9) / 45.3(6.7)$ \\
\hline VC (l) & $1.95(0.59)$ & $1.98(0.54)$ & $1.94(0.64)$ \\
\hline VC (\% pred) & 48.9 (11.9) & $50.0(11.6)$ & $47.7(12.2)$ \\
\hline $\operatorname{FEV}_{1}(1)$ & $0.83(0.28)$ & $0.81(0.29)$ & $0.85(0.28)$ \\
\hline $\mathrm{FEV}_{1}(\%$ pred $)$ & $29.8(9.8)$ & $29.8(10.3)$ & $29.7 \quad(9.4)$ \\
\hline $\mathrm{FEV}_{1} / \mathrm{VC}(\%)$ & $42.9 \quad(12.9)$ & $40.8 \quad(12.1)$ & 45.1 (13.4) \\
\hline Haematocrit (\%) & $47.2(5.5)$ & $46.4 \quad(5.3)$ & 47.9 (5.7) \\
\hline Observation time (months) & $40.9 \quad(19.9)$ & 38.9 (19.7) & $42.8 \quad(20.1)$ \\
\hline Steroids (no. of pts) & 39 & 20 & \\
\hline e (hours) & & & 13.5 (4.4) \\
\hline
\end{tabular}

$\mathrm{BMI}=$ body mass index; $\mathrm{PaO}_{2}=$ arterial partial oxygen tension; $\mathrm{PaCO}_{2}=$ arterial partial carbon dioxide tension; $\mathrm{VC}=$ vital capacity; $\mathrm{FEV}_{1}=$ forced expiratory volume in one second. $* \mathrm{p}<0.05$ control versus LTOT group.

as lasting more than six months. Patients on LTOT received oxygen from an oxygen concentrator at a flow rate adjusted to raise resting $\mathrm{PaO}_{2}$ above $8.7 \mathrm{kPa}(65 \mathrm{mmHg})$. The prescribed oxygen breathing time was at least 17 hours per 24 hours. The compliance with the treatment was checked by reading the oxygen meter built into the oxygen concentrator. Patients were strongly advised to stop smoking and all declared to be non-smokers at the time of prescription of oxygen. Informed consent was obtained from each patient. The protocol of the study was approved by the ethics committee of the Institute.

After allocation to the control or treatment groups patients were followed closely for at least three years or until death. They were visited at home monthly by a respiratory nurse and were seen once every three months in an outpatient clinic by the physician responsible for LTOT, being admitted to hospital for other treatment as necessary. There were no dropouts during the study. All deaths and causes of death were recorded. Each living patient was contacted at the end of the study in December 1994 by a respiratory nurse.

\section{STATISTICAL ANALYSIS}

Means and standard deviations of measured variables were calculated. Differences between groups were assessed using an unpaired $t$ test, $\mathrm{p}$ values of $<0.05$ being considered statistically significant. Survival analysis was performed using Cox's proportional hazards analysis for the factors that might influence survival. ${ }^{11}$ The model also provides the possibility for checking the statistical significance of the influences on survival of one or more variables studied. The statistical significance of the differences between two groups was assessed using Cox's regression model and checked by the WilcoxonMann-Whitney type non-parametric test. In particular, the Gehan-Wilcoxon statistic was used to confirm the lack of difference in survival between the control and treatment groups. Statistica and NCSS packages were used for the computation procedures.

\section{Results}

The treatment group consisted of 103 men and 32 women of mean age 61.2 years (range
Table 2 Causes of death in control and LTOT groups

\begin{tabular}{lcl}
\hline Causes of death & $\begin{array}{l}\text { Control group } \\
(n=32)\end{array}$ & $\begin{array}{l}\text { LTOT group } \\
(n=38)\end{array}$ \\
\hline COPD & 22 & 21 \\
Myocardial infarction & 3 & 1 \\
Sudden death at home & - & 6 \\
Death during sleep & 1 & 2 \\
Lung cancer & 1 & 2 \\
Other neoplasm & 1 & 2 \\
Pulmonary embolism & 1 & 1 \\
Gastric haemorrhage & 1 & 1 \\
Suicide & - & 1 \\
Pneumothorax & - & - \\
Cerebral haemorrhage & 1 & - \\
Car accident & 1 & \\
\hline
\end{tabular}

40-79). On average the patients were observed for 40.9 months (range 2-85). Mean values of body mass index (BMI), spirometric values, blood gas tensions, and haematocrit at entry to the study are shown in table 1 . All patients suffered from severe airflow limitation with mean (SD) forced expiratory volume in one second $\left(\mathrm{FEV}_{1}\right) 0.83(0.28) 1$.

The control and treatment groups were well matched in all measured variables. The only significant difference at entry to the study was the value of $\mathrm{PaO}_{2}$ (table 1). To check for the influence of $\mathrm{PaO}_{2}$ on survival the Cox's regression coefficients corresponding to the independent variable $\mathrm{PaO}_{2}$ were calculated separately for each group and provided no evidence that the $\mathrm{PaO}_{2}$ value influenced the survival of the patients in the study.

In the group receiving LTOT the $\mathrm{PaO}_{2}$ while breathing oxygen was increased in all patients to more than $8.7 \mathrm{kPa}(65 \mathrm{mmHg})$ (mean $\mathrm{PaO}_{2} /$ $\left.\mathrm{O}_{2} 9.9(1.1) \mathrm{kPa}(74.0(7.9) \mathrm{mmHg})\right)$. Only in seven patients (three of whom were survivors) was the $\mathrm{PaO}_{2}$ increased by less than $1 \mathrm{kPa}$ while breathing oxygen. The mean time spent breathing oxygen, calculated from the oxygen concentrator meter readings, was 13.5 (4.4) hours/ day.

Seventy patients died during the observation period, 32 in the control group and 38 in the LTOT group. The causes of death are presented in table 2. Most of the deaths in both groups were due to progression of the COPD.

The cumulative survival rate of the total group in the first year was $88 \%$, in the second year $77 \%$, and in the third year $66 \%$. Survival

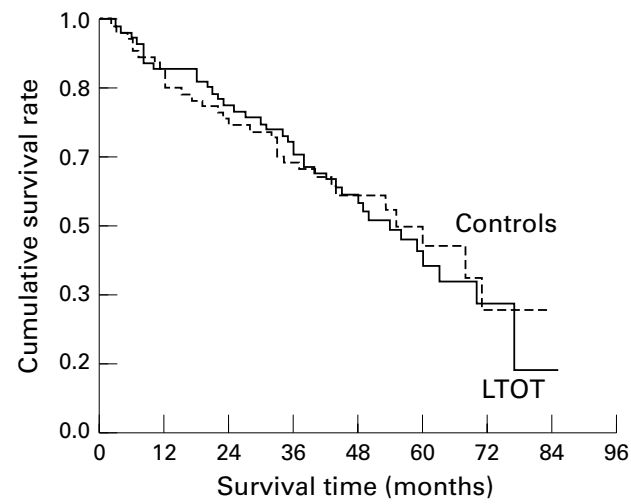

Figure 1 Cumulative survival rate in LTOT group and controls. Difference between groups is not statistically significant $(p=0.892)$. 


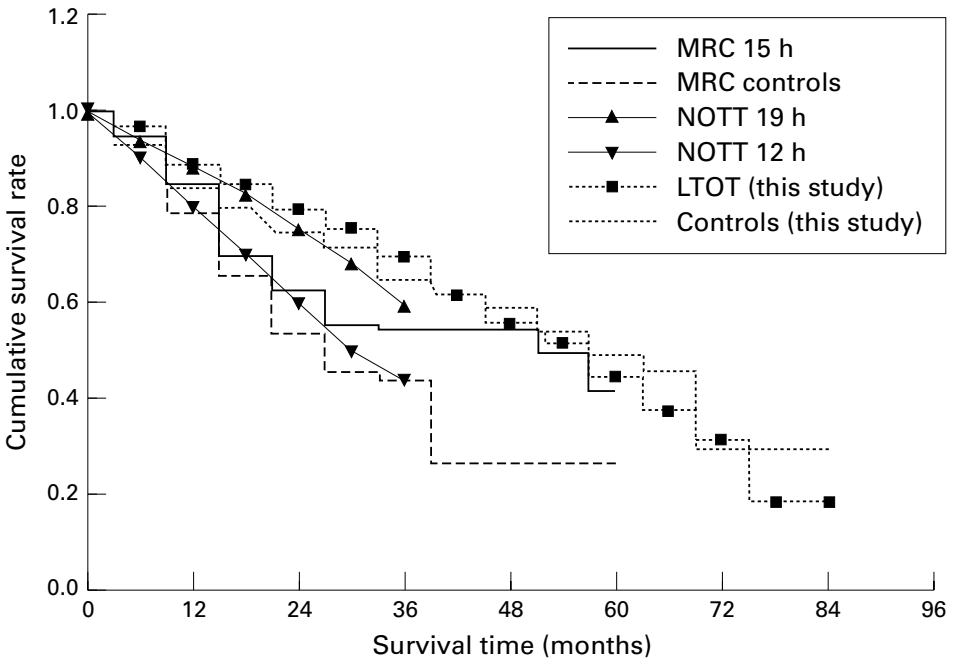

Figure 2 Cumulative survival rate in the LTOT group and control patients compared with the survival of patients in the MRC and NOTT studies.

Table 3 Mean (SD) differences in studied variables in survivors versus non-survivors in the total study group

\begin{tabular}{|c|c|c|c|}
\hline Variable & $\begin{array}{l}\text { Survivors } \\
(n=65)\end{array}$ & $\begin{array}{l}\text { Non-survivors } \\
(n=70)\end{array}$ & $p$ value \\
\hline Age (years) & $59.4 \quad(8.3)$ & 62.9 (8.4) & 0.02 \\
\hline $\mathrm{M} / \mathrm{F}$ & $50 / 15$ & $53 / 17$ & \\
\hline BMI $\left(\mathrm{kg} / \mathrm{m}^{2}\right)$ & $25.1(4.9)$ & $22.5 \quad(4.3)$ & $<0.001$ \\
\hline $\mathrm{PaO}_{2}(\mathrm{kPa} / \mathrm{mmHg})$ & $8.1(0.4) / 60.5(2.9)$ & $8.1(0.4) / 60.4(2.9)$ & NS \\
\hline $\mathrm{PaCO}_{2}(\mathrm{kPa} / \mathrm{mmHg})$ & $5.9(0.9) / 44.5(6.8)$ & $5.8(0.9) / 43.6(6.7)$ & NS \\
\hline VC (1) & $2.06(0.57)$ & $1.85(0.59)$ & 0.038 \\
\hline VC (\% pred $)$ & $51.0 \quad(11.8)$ & $47.0 \quad(11.8)$ & NS \\
\hline $\mathrm{FEV}_{1}(\mathrm{l})$ & $0.89(0.30)$ & $0.78(0.25)$ & $<0.001$ \\
\hline $\mathrm{FEV}_{1}(\%$ pred $)$ & $31.2(10.4)$ & $28.4(9.2)$ & NS \\
\hline $\mathrm{FEV}_{1} / \mathrm{VC}(\%)$ & $42.8 \quad(12.6)$ & $43.1 \quad(13.3)$ & NS \\
\hline Haematocrit (\%) & $47.9(6.1)$ & $46.5(4.8)$ & NS \\
\hline Observation time (months) & $52.0 \quad(12.9)$ & $30.5 \quad(19.7)$ & $<0.001$ \\
\hline Steroids (no. of pts) & 13 & 26 & NS \\
\hline
\end{tabular}

analysis using Cox's regression model showed no differences in survival between oxygen treated and control groups (fig 1). The hazard ratio to be a member of the control group is equal to 0.916 with a $95 \%$ confidence interval of 0.571 to 1.471 (the value 1 , representing an equal hazard for LTOT and control groups, is well covered by this interval). Additional analysis using the Gehan-Wilcoxon statistic with the value of $-0.018(\mathrm{p}=0.49)$ confirmed the lack of difference between the control and treatment groups.
Figure 2 shows the survival curves of our patients (in the LTOT and control groups) superimposed on the survival curves of the MRC and NOTT studies. The survival of our patients with COPD with moderate hypoxaemia in both the control and treatment groups was better than of those with severe hypoxaemia in the MRC and NOTT studies; however, there is a considerable overlap.

The differences in the studied variables between survivors and non-survivors in the total group are presented in table 3. Patients who survived were significantly younger (59.4 vs 62.9 years, $\mathrm{p}=0.02$ ), had better lung function (VC 2.061 vs $1.851, \mathrm{p}=0.038$ and $\mathrm{FEV}_{1} 0.891$ vs $0.781, \mathrm{p}<0.001)$, and higher BMI $(25.1 \mathrm{~kg} /$ $\mathrm{m}^{2}$ vs $22.5 \mathrm{~kg} / \mathrm{m}^{2}, \mathrm{p}<0.001$ ) than non-survivors. The differences in the studied variables between survivors and non-survivors in the control and treatment groups separately are presented in table 4 . In the oxygen treated group better lung function (VC 2.121 in survivors vs 1.801 in non-survivors $(p=0.037)$ and $\mathrm{FEV}_{1} 0.961$ vs 0.771 , respectively $(\mathrm{p}=$ $0.004)$ ) and higher BMI (25.6 vs $22.6 \mathrm{~kg} / \mathrm{m}^{2}$, $\mathrm{p}=0.017$ ) predicted better survival. In the control group patients who survived were significantly younger $(60.8$ vs 64.2 years, $p<0.05)$ and had higher BMI (24.6 vs $22.5 \mathrm{~kg} / \mathrm{m}^{2}$, $\mathrm{p}<0.05)$ than those who died.

Interestingly, survivors in the treatment group breathed oxygen for a shorter time (12.7 hours/day) than non-survivors (14.2 hours/ day), although the difference was not statistically significant. We have found no differences in survival in patients using oxygen for 15 or more hours/day compared with those less compliant $(p=0.376)$. When oxygen use was stratified there were 10 survivors and 11 nonsurvivors who breathed oxygen for less than 12 hours, 11 patients in each group who used oxygen for 12-15 hours, and only nine survivors compared with 16 non-survivors who breathed oxygen for more than 15 hours/day.

The mean $\mathrm{PaO}_{2}$ in our patients was $8.0 \mathrm{kPa}$ $(60.4 \mathrm{mmHg})$ with 74 patients having $\mathrm{a}^{\mathrm{PaO}_{2}}$ of $\leq 8.0 \mathrm{kPa}$ and 61 patients with a $\mathrm{PaO}_{2}$ of $>8.0 \mathrm{kPa}$. No differences in survival were found in these subgroups of patients (fig 3 ). We also found that, among the LTOT group who sur-

Table 4 Comparison of mean (SD) studied variables in survivors and non-survivors in the control and LTOT groups

\begin{tabular}{|c|c|c|c|c|}
\hline & \multicolumn{2}{|l|}{ Controls } & \multicolumn{2}{|l|}{ LTOT } \\
\hline & $\begin{array}{l}\text { Survivors } \\
(n=35)\end{array}$ & $\begin{array}{l}\text { Non-survivors } \\
(n=32)\end{array}$ & $\begin{array}{l}\text { Survivors } \\
(n=30)\end{array}$ & $\begin{array}{l}\text { Non-survivors } \\
(n=38)\end{array}$ \\
\hline & $60.8(7.3)$ & $64.2 \quad(8.8) \ddagger$ & $57.9 \quad(9.3)$ & $61.8 \quad(8.0)$ \\
\hline $\mathrm{M} / \mathrm{F}$ & $26 / 9$ & $26 / 6$ & $24 / 6$ & $27 / 11$ \\
\hline $\mathrm{PaO}_{2}(\mathrm{kPa} / \mathrm{mmHg})$ & $8.2(0.4) / 61.2(2.7) \rrbracket$ & $8.2(0.4) / 61.4(2.8)$ & $7.9(0.4) / 59.6(2.9)$ & $7.9(0.3) / 59.5(2.6) \dagger$ \\
\hline $\mathrm{PaCO}_{2}(\mathrm{kPa} / \mathrm{mmHg})$ & $5.7(0.9) / 43.1(6.6)$ & $5.7(0.9) / 42.5(6.8)$ & $6.2(0.9) / 46.2(6.7)$ & $5.9(0.9) / 44.6(6.6)$ \\
\hline VC (1) & $2.00(0.56)$ & $1.91(0.51)$ & $2.12(0.59)^{* *}$ & $1.80(0.66)$ \\
\hline VC (\% pred) & 51.7 (12.8) & $48.1(10.1)$ & $50.0(10.5)$ & 46.1 (13.2) \\
\hline $\mathrm{FEV}_{1}(1)$ & $0.84(0.32)$ & $0.78(0.25)$ & $0.96(0.27)^{* *}$ & $0.77(0.25)$ \\
\hline $\mathrm{FEV}_{1}(\%$ pred $)$ & 30.6 (11.3) & $29.0(9.2)$ & $32.2(9.2)$ & $28.0(9.2)$ \\
\hline $\mathrm{FEV}_{1} / \mathrm{VC}(\%)$ & 41.7 (13.3) & $39.9(10.8)$ & $44.1 \quad(11.8)$ & $45.9(14.6)$ \\
\hline Haematocrit (\%) & $47.2(5.8)$ & $45.7(4.7)$ & $48.8(6.5)$ & $47.2(4.9)$ \\
\hline Observation time (months) & $49.6(12.8)$ & 27.2 (19.4)㧊 & $54.8(12.8)^{* * *}$ & $33.2(19.8)$ \\
\hline $\mathrm{O}_{2}$ breathing time (hours) & - & - & $12.7(4.1)$ & $14.2(4.6)$ \\
\hline $\mathrm{BMI}\left(\mathrm{kg} / \mathrm{m}^{2}\right)$ & $24.6(4.6)$ & $22.5 \quad(4.1) \ddagger$ & $25.6(5.4)^{*}$ & $22.6 \quad(4.5)$ \\
\hline Steroids (no. of pts) & 9 & & 4 & 15 \\
\hline $\mathrm{PaO}_{2} / \mathrm{O}_{2}(\mathrm{kPa} / \mathrm{mmHg})$ & & & $9.9(1.3) / 74.5(9.8)$ & $9.8(0.9) / 73.7(6.4)$ \\
\hline
\end{tabular}

$* \mathrm{p}<0.05 ; * * \mathrm{p}<0.01 ; * * \mathrm{p}<0.001$ survivors vs non-survivors in LTOT group.

$+\mathrm{p}<0.05$ between non-survivors in both groups.

$\neq \mathrm{p}<0.05$; $\neq \ddagger \mathrm{p}<0.01$ survivors vs non-survivors in controls

$\$ \mathrm{p}<0.05$ between survivors in both groups. 


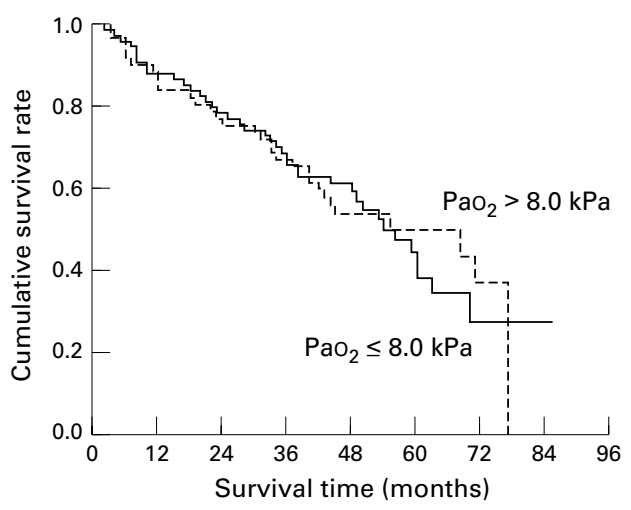

Figure 3 Cumulative survival rate in the total group stratified for arterial oxygen tension $\left(\mathrm{PaO}_{2}\right)$. No difference in survival was found in patients with $\mathrm{PaO}_{2} \leq 8.0 \mathrm{kPa}$ and $\mathrm{PaO}_{2}>8.0 \mathrm{kPa}(p=0.906)$.

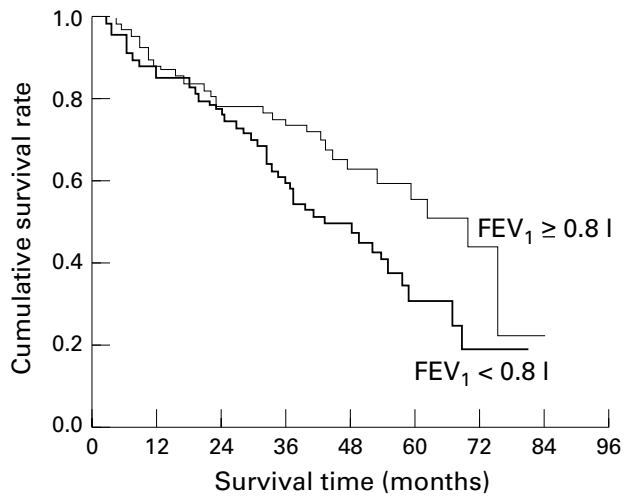

Figure 4 Cumulative survival rate in the total group stratified for forced expiratory volume in one second $\left(F E V_{1}\right)$. Patients with $F E V_{1} \geq 0.81$ survived significantly longer than those with $F E V_{1}<0.8 l(p=0.028)$.

vived, seven resumed smoking as judged by an elevated carboxyhaemoglobin level. Thirty nine patients $(29 \%)$ used long term steroids (more than six months), seven inhaled steroids, six intramuscular, and 26 oral preparations. Long term steroids were used by twice as many patients who did not survive $(\mathrm{n}=26)$ as survivors $(n=13)$, but the difference did not reach statistical significance (table 3 ).

Using Cox's proportional hazards analysis on the pooled sample (135 patients) we found that the cut off value of $\mathrm{FEV}_{1}$ of 0.81 was significantly related to survival rates (fig 4). Survival rates also improved significantly with increasing BMI, patients with a BMI of $>25 \mathrm{~kg} /$ $\mathrm{m}^{2}$ having higher survival rates than those with a BMI of $<20 \mathrm{~kg} / \mathrm{m}^{2}$ (fig 5). We have also found that BMI was closely related to $\mathrm{FEV}_{1}(r=$ $0.345, \mathrm{p}<0.001)$. Additional analysis based on Cox's regression model was performed to establish the influence of both parameters on survival, taking into account the positive correlation between them. The analysis with two independent variables showed that, if BMI and $\mathrm{FEV}_{1}$ were mutually adjusted, then only BMI had a significant positive influence on survival. Corresponding $\mathrm{p}$ values were 0.14 for $\mathrm{FEV}_{1}$ and 0.035 for BMI. Hazard ratios $(95 \%$ confidence interval) estimated by the Cox's

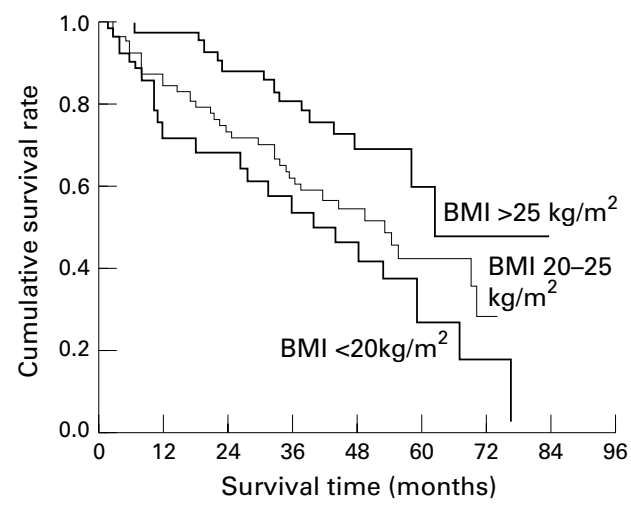

Figure 5 Cumulative survival rate in the total group stratified for body mass index (BMI). Patients with BMI $>25 \mathrm{~kg} / \mathrm{m}^{2}$ survived significantly longer than those with $B M I<20 \mathrm{~kg} / \mathrm{m}^{2}(p=0.005)$.

regression model with $\mathrm{BMI}$ and $\mathrm{FEV}_{1}$ as independent variables were $0.992(0.984$ to 1.002) for $\mathrm{FEV}_{1}$ and 0.942 (0.905 to 0.996) for BMI. Additional residual regression analysis was performed to check if BMI had a significant influence on survival after adjusting it first for corresponding $\mathrm{FEV}_{1}$. The analysis produced a new variable - the residual values of BMI. After taking the residual values of BMI as the independent variable the analysis showed that BMI still had a significant influence on survival $(\mathrm{p}=0.05)$. The hazard ratio for BMI adjusted for $\mathrm{FEV}_{1}$ was 0.950 (95\% CI 0.908 to 0.999 ). The results of these analyses prove that there is a casual relationship between $\mathrm{FEV}_{1}$ and $\mathrm{BMI}$ and that BMI is a significant predictor of survival independently of $\mathrm{FEV}_{1}$. No other physiological variable studied predicted significant differences in survival.

\section{Discussion}

The prescription of LTOT to patients with COPD with moderate hypoxaemia did not prolong life. Moreover, within the oxygen treated group no correlation was found between oxygen use and survival.

The beneficial effect of LTOT in preventing the progression of pulmonary hypertension is well known ${ }^{12-14}$ but this treatment does not influence the progression of the airflow limitation. ${ }^{15-17}$ To date only two controlled studies have been reported on the effects of long term oxygen breathing in patients with COPD with advanced respiratory failure - the MRC and NOTT studies ${ }^{12}$ - both of which found that breathing oxygen for more than 15 hours/day substantially prolonged survival. The longer the oxygen breathing time the better survival was observed.

Although the upper limit of $\mathrm{PaO}_{2}$ for inclusion in these studies was set at $8 \mathrm{kPa}(60 \mathrm{mmHg})$, most of the patients had a $\mathrm{PaO}_{2}$ of less than $7.3 \mathrm{kPa}(55 \mathrm{mmHg})$. In the MRC study the mean $\mathrm{PaO}_{2}$ on air was only $6.7 \mathrm{kPa}$ $(50.4 \mathrm{mmHg})$ for the treated group and $6.9 \mathrm{kPa}$ $(51.5 \mathrm{mmHg})$ for the controls, whereas in the NOTT study it was $6.8 \mathrm{kPa}(50.8 \mathrm{mmHg})$ for the continuous therapy group and $6.9 \mathrm{kPa}$ 
(51.5 $\mathrm{mmHg}$ ) for the nocturnal oxygen group. Mean $\mathrm{PaO}_{2}$ in our patients was much higher $(8.0 \mathrm{kPa}(60.4 \mathrm{mmHg}))$. Although it might have been anticipated, no differences in survival were found in subgroups of patients with $\mathrm{PaO}_{2}$ $\leq 8 \mathrm{kPa}$ and $>8.0 \mathrm{kPa}$ at entry to the study.

Our treated and control groups were well matched at the beginning of the study. The only statistically significant difference (although clinically trivial) between the groups was in $\mathrm{PaO}_{2}$ which was lower in the LTOT group. This difference was probably due to a narrow range (only $1.3 \mathrm{kPa}(10 \mathrm{mmHg})$ ) of inclusion $\mathrm{PaO}_{2}$ values. Such a range restricted the standard deviation, thereby increasing the significance of small differences in mean values. Moreover, the $\mathrm{PaO}_{2}$ did not influence the survival in either group or the study group as a whole, which is the best evidence that the baseline differences were not important.

In the two landmark studies ${ }^{12}$ survival was positively associated with the number of hours of oxygen breathing. In our study compliance with the treatment was similar to that of the MRC trial. However, we observed no differences between oxygen use in survivors (12.7 hours/day) and non-survivors (14.2 hours/day). When we analysed a subgroup of patients who breathed oxygen for more than 15 hours/day there were more non-survivors than survivors in that group. This finding may be explained by the fact that surviving patients were younger, had better lung function, and did not feel the need to comply with the prescribed treatment (17 hours and more). Similarly, in a study by the ANTADIR group $65 \%$ of patients with $\mathrm{PaO}_{2}>8.0 \mathrm{kPa}(60 \mathrm{mmHg})$ decreased their daily oxygen use to below 15 hours because they found the longer treatment not necessary. ${ }^{18}$

From two recent studies from Sweden ${ }^{19}$ and the ANTADIR group in France ${ }^{20}$ it appears that survival in patients with a higher prescription of oxygen is inferior to that in patients with a lower oxygen prescription and may reflect the physician's perception of the severity of the disease.

Survival in our group was similar to that of patients in the IPPB trial with a similar degree of airflow limitation and no hypoxaemia. ${ }^{21}$ Survival in both the treatment and control groups was better than survival of the patients in the MRC trial ${ }^{1}$ with more advanced airflow limitation $\left(\mathrm{FEV}_{1} 0.761\right.$ in oxygen treated group, 0.631 in controls) and more severe hypoxaemia. It was also better than the survival of the nocturnal oxygen therapy group and similar to the survival in the continuous oxygen treatment group in the NOTT trial. ${ }^{2}$ In a comparison of patients in the IPPB trial without hypoxaemia with NOTT patients with the same degree of airway limitation, Athonisen has found that the correction of hypoxaemia improved the survival rates of the continuous oxygen therapy group to the rate of survival of patients with no blood gas disturbances, as opposed to the less favourable survival of the nocturnal oxygen group. ${ }^{22}$ The correction of hypoxaemia in the MRC trial also improved the survival in oxygen treated patients compared with controls. ${ }^{1}$ Oxygen treatment was of benefit to the patients such as those in the MRC and NOTT studies, but not to our patients. There was, however, a considerable overlap in the survival of our patients and those from the abovementioned studies.

Patients receiving LTOT increased their $\mathrm{PaO}_{2}$ on average by $2 \mathrm{kPa}$ while breathing oxygen. Almost all improved their oxygenation by at least $1 \mathrm{kPa}$, which is in accordance with the UK guidelines for prescribing oxygen. ${ }^{23}$ An equal number of non-responders was found among the survivors and non-survivors, suggesting that this factor did not influence the survival.

This comparison of our data with that in the literature clearly confirms that survival in patients with COPD is influenced by airway limitation and that LTOT prolongs life only when severe hypoxaemia ensues.

In our patients survival depended on lung function and age at entry to the study. Patients who survived had better preserved lung function and were significantly younger. In many previous studies the age has also proved to be a significant predictor of survival. ${ }^{421224}$

In a number of studies of patients with COPD $^{2526}$ survival was influenced by the body mass. Undernourished patients did not do so well as those who were overweight ${ }^{20}$ and this effect was independent of the lung function. ${ }^{26}$ Also, our patients who survived had a significantly higher BMI than those who did not survive and the survival rate improved with increasing body mass independently of $\mathrm{FEV}_{1}$, as well as after adjusting $\mathrm{BMI}$ for $\mathrm{FEV}_{1}$, similar to the results of the IPPB trial. ${ }^{26}$

We have found that, after mutually adjusting BMI and $\mathrm{FEV}_{1}$, only BMI proved to have a significant influence on survival. This may be explained by the extremely narrow range of very low $\mathrm{FEV}_{1}$ values. However, $\mathrm{FEV}_{1}$ proved to be significantly lower in non-survivors and the value of 0.81 resulted in significant differences in survival in those with less and more advanced airway limitation.

Another factor that should be taken into account in studying survival is stopping smoking. It is well known that quitting smoking slows the decline in $\mathrm{FEV}_{1}{ }^{2728}$ and improves the survival, although such an influence becomes apparent only after approximately six years of follow up. ${ }^{29}$ All our patients declared to be non-smokers when starting LTOT, however seven had resumed smoking as judged by raised carboxyhaemoglobin level at 1-3 months after entering the study. All these patients survived. The carboxyhaemoglobin level was not checked in the control group. It is extremely difficult to draw any conclusion from this finding due to the limited number of patients in whom we could study these influences.

It has been suggested that use of long term corticosteroids in women with COPD may adversely affect survival. ${ }^{30}$ Such treatment was prescribed in $29 \%$ of our patients and twice as many patients receiving steroids died as survived. However, this difference did not reach statistical significance. As we included only patients with COPD with fixed airway ob- 
struction, the prescription of steroids reflected the severity of the disease.

We conclude that, in patients with COPD with chronic airflow limitation but moderate hypoxaemia, there is no difference in survival rates between patients treated and not treated with domiciliary oxygen. In addition, oxygen use for longer periods did not improve the survival rate. These results suggest that prescription of LTOT in this specific group of patients with COPD should be done more cautiously, reserving this expensive treatment for patients with severe hypoxaemia as in the UK guidelines. ${ }^{23}$

The authors wish to thank the following physicians from the regional LTOT centres for their participation in the study: M Czajkowska-Malinowska (Bydgoszcz), A Kubica (Bystra), J Dobrzańska (Chełm), G Staśkiewicz (Ciechanów), M Filipowska and L Sokołowska (Kraków), E Sporna (Łódź), T Izbicka (Suwałki), M-J Pułka (Wrocław).

1 Medical Research Council Working Party. Long-term domiciliary oxygen therapy in chronic hypoxic cor pulmonale complicating chronic bronchitis and emphysema. Lancet 1981;i:681-6.

2 Nocturnal Oxygen Therapy Trial Group. Continuous or nocturnal oxygen therapy in hypoxemic chronic lung disease: a clinical trial. Ann Intern Med 1980;93:391-8.

3 Skwarski K, MacNee W, Wraith PK, Sliwiński P, Zieliński J. Predictors of survival in patients with chronic obstructive pulmonary disease treated with long-term oxygen therapy. Chest 1991;100:1522-7.

4 Dubois P, Jamart J, Machiels J, Smeets F, Lulling J. Prognosis of severely hypoxemic patients receiving long-term oxygen therapy. Chest 1994;105:469-74

5 Zieliński J, Sliwiński P. Indications and methods of longterm oxygen therapy. Eur Respir Rev 1991;1:536-40.

6 Levi Valensi P, Aubry P, Donner CF, Robert B, Ruhle KH, Weitzenblum $\mathrm{E}$ for the task group of SEP. Recommendations for long term oxygen therapy. Eur Respir f $1989 ; 2: 160-4$.

7 Conference Report. Further recommendations for prescribing and supplying long-term oxygen therapy. Am Rev Respir Dis 1988;138:745-7.

8 Ström K, Boe J. A national register for long-term oxygen therapy in chronic hypoxia: preliminary report. Eur Respir therapy in chron

9 Górecka D, Sliwiński P, Zieliński J. Adherence to entry criteria and one year experience of long-term oxygen therapy in Poland. Eur Respir 7 1992;5:848-52.

10 Zieliński J, Sliwiński P, Tobiasz M, Górecka D. Long-term oxygen therapy in Poland. Monaldi Arch Chest Med 1993; 48:479-80.

11 Cox DR. Regression model and life tables. IR Stat Soc (Series B) 1972;34:187-200.

12 Timms RM, Khaja FU, Williams GW. The Nocturnal Oxygen Trial Group. Haemodynamic response to oxygen therapy in chronic obstructive pulmonary disease. Ann Intern Med 1985;102:29-36.

13 Weitzenblum E, Sautegeau A, Ehrhart M, Mammosser M, Pelletier A. Long-term oxygen therapy can reverse the progression of pulmonary hypertension in patients with chronic obstructive pulmonary disease. Am Rev Respir Dis 1985;131:493-6.

14 Tobiasz M, Sliwiñski P, Hawrytkiewicz I, Patasiewicz G, Zieliñski J. Pulmonary haemodynamics after 6 years of oxygen therapy

15 Weitzenblum E, Oswald M, Apprill M, Ratomaharo J, Kessler R. Evolution of physiological variables in patients with chronic obstructive pulmonary disease before and during long-term oxygen therapy. Respiration 1991.58: $126-31$

16 Cooper CB, Howard P. An analysis of sequential physiologic changes in hypoxic cor pulmonale during long-term oxychanges in hypoxic cor pulmonale

17 Sliwiński P. Effects of long-term oxygen therapy in patients with chronic obstructive pulmonary disease. Pneumonol Alergol Pol 1992;60:20-7.

18 Barihoux C, Pepin JL, Deschaux-Blanc C, et al. Oxygenotherapie au long cours a domicile. Respect de la prescription medicale et observance d'une duree quotidienne d'au moins 15 heures. Rev Mal Resp 1994;11: $37-45$.

19 Ström K, Boe J. The Swedish Society of Chest Medicine: quality assessment and predictors of survival in long-term domiciliary oxygen therapy. Eur Respir f 1991;4:50-8.

20 Chailleux E, Binet F, Sadoul P et Commission MedicoTechnique et Sociale de L'ANTADIR. Facteurs pronostiques de la survie des insuffisants respiratoires obstructifs traites par oxygenotherapie a long terme. Rev Mal Resp 1992;9:603-11.

21 Anthonisen NR, Wright EC, Hodgkin JE, and the IPPB Trial group. Prognosis in chronic obstructive pulmonary disease. Am Rev Respir Dis 1986;133:14-20.

22 Anthonisen NR. Prognosis in chronic obstructive pulmonary disease:results from multicenter clinical trials. Am Rev Respir Dis 1989;140:S95-9.

23 The Drug Tariff. Introduction of oxygen concentrators to the domiciliary oxygen therapy service. Publication No. FNP 398. London: Department of Health and Social Security, 1986.

24 Dallari R, Barozzi G, Pinelli G, Merighi V, Grandi P, Manzotti M, et al. Predictors of survival in subjects with chronic obstructive pulmonary disease treated with longchronic obstructive pulmonary disease treated wit

25 Vanderbergh E, Van de Woestyne KP, Gyselen A. Weight changes in the terminal stages of chronic obstructive pulchanges in the terminal stages of chronic obstructive pul-

26 Wilson DO, Rogers RM, Wright EC, Anthonisen NR. Body weight in chronic obstructive pulmonary disease. Am Rev weight in chronic obstructive
Respir Dis 1989;139:1435-8

27 Fletcher C, Peto R. The natural history of chronic airflow obstruction. BMF 1977;1:1645-8.

28 Anthonisen NR, Connet JE, Kiley JP, et al for the Lung Health Study Research Group. Effects of smoking intervention and use of an inhaled anticholinergic bronchodilator on the rate of decline of $\mathrm{FEV}_{1}$. $\mathcal{F} A M A 1994 ; 272$ 1497-505.

29 Postma DS, Sluiter HJ. Prognosis of chronic obstructive pulmonary disease: the Dutch experience. Am Rev Respir Dis $1989 ; \mathbf{1 4 0}$ :S100-5.

30 Ström K. Survival of patients with chronic obstructive pulmonary disease receiving long-term oxygen therapy. Am Rev Respir Dis 1993;147:585-91. 